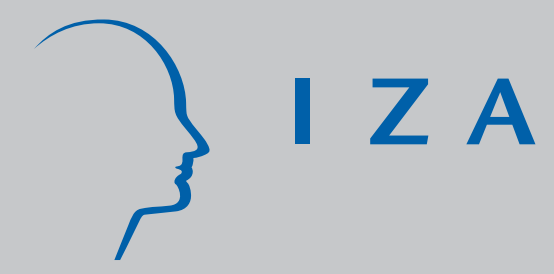

IZADP No. 2812

Hooliganism and Police Tactics: Should Tear Gas Make Crime Preventers Cry?

Panu Poutvaara

Mikael Priks

May 2007 


\title{
Hooliganism and Police Tactics: Should Tear Gas Make Crime Preventers Cry?
}

\author{
Panu Poutvaara \\ University of Helsinki \\ and IZA \\ Mikael Priks \\ CES, University of Munich
}

\author{
Discussion Paper No. 2812 \\ May 2007
}

IZA

P.O. Box 7240

53072 Bonn

Germany

Phone: +49-228-3894-0

Fax: +49-228-3894-180

E-mail: iza@iza.org

\begin{abstract}
Any opinions expressed here are those of the author(s) and not those of the institute. Research disseminated by IZA may include views on policy, but the institute itself takes no institutional policy positions.

The Institute for the Study of Labor (IZA) in Bonn is a local and virtual international research center and a place of communication between science, politics and business. IZA is an independent nonprofit company supported by Deutsche Post World Net. The center is associated with the University of Bonn and offers a stimulating research environment through its research networks, research support, and visitors and doctoral programs. IZA engages in (i) original and internationally competitive research in all fields of labor economics, (ii) development of policy concepts, and (iii) dissemination of research results and concepts to the interested public.
\end{abstract}

IZA Discussion Papers often represent preliminary work and are circulated to encourage discussion. Citation of such a paper should account for its provisional character. A revised version may be available directly from the author. 


\section{ABSTRACT \\ Hooliganism and Police Tactics: Should Tear Gas Make Crime Preventers Cry?*}

Hooliganism is on the rise and different countries use different strategies to combat it. We introduce a model where hooligans reap utility from violence and social identity and study the effects of different police strategies. We find that an increase in discriminative policing, provided by intelligence units, for example, always reduces violence. Under the right circumstances, it may also lead to larger supporter clubs and a significant drop in violence. Indiscriminate policing, such as the use of teargas or random jailing of potential law breakers, may, however, backfire and result in smaller and more brutal groups.

JEL Classification: D71, D74

Keywords: violence, hooliganism, identity, police

Corresponding author:

Panu Poutvaara

Department of Economics

University of Helsinki

P.O. Box 17 (Arkadiankatu 7)

FIN-00014 Helsinki

Finland

E-mail: panu.poutvaara@helsinki.fi

\footnotetext{
* We thank Lawrence Blume, Edward Glaeser, John Matsusaka, Andrei Shleifer, Jenny SäveSöderbergh and seminar and conference participants at Tilburg University, the University of Munich, IIES and SOFI at Stockholm University, FIEF in Stockholm, the EEA Meeting in Amsterdam in 2005, the Public Choice Society Meeting in Baltimore in 2004, and the Public Economic Theory Meeting in Marseille in 2005 for helpful comments.
} 


\section{Introduction}

Supporter violence is a very old phenomenon. Already in AD 59, a huge hooligan incident took place at gladiator games in the amphitheater in Pompeii. The citizens of Pompeii and the neighboring city Nuceria were supporting different gladiators and the antagonism between the fans resulted in a large number of Nucerians being killed (Tacitus Annals, AD 109, book XIV, paragraph 17). In 532, in Constantinople, team support at the "Hippodrome" escalated from insults to mob riots, which finally laid the town in ruins. Much later, in 1314, football was banned in London for the fear of tumult and disorder surrounding the games (Armstrong 1998). ${ }^{1}$ Football hooliganism has in modern time led to several catastrophes, including, for example, the tragedy in Heysel stadium in Belgium in 1985 that resulted in chaos and death of 39 persons. In the last few years, hooliganism has escalated and resulted in several deaths in Europe. Also Argentina and Brazil are currently experiencing extreme levels of supporter violence where stabbings and shootings are common.

To reduce hooligan violence, governments have traditionally used intense and often indiscriminate policing. While the police in countries in southern Europe and in Latin America still tends to use harsh and indiscriminate policing, sometimes being armed with for example water canons, tear gas and rubber-bullet weapons, the English police has changed strategy in favor of more discriminative policing (Carnibella et al. 1996 and Footballnetwork.org). This includes both the use of technical devices, such as surveillance cameras, and of special trained intelligence personnel. Other countries have followed the English police. For example, Sweden has since 1992 employed intelligence units monitoring violent supporters. In Denmark, the police changed strategy in the mid-1990s in favor of less armed police using special cars to come close to the violent hooligans in order to be able to specifically target them. ${ }^{2}$

\footnotetext{
${ }^{1}$ Carnibella et al. (1996) report a large number of other early incidents.

${ }^{2} \mathrm{An}$ example of the different schools of policing comes from the aftermath of the recent hooligan violence that surrounded the Champions league game between AS Roma and Manchester United on April 4, 2007. The Manchester United spokesman Phil Townsend stated "In what the club views as a serious over-reaction, local police handed out indiscriminate beatings to United supporters" (BBC, April 5, 2007).
} 
In this paper we introduce a model of hooliganism to study how different types of police strategies affect membership and aggregate violence. To the best of our knowledge, hooliganism has not been studied previously in the economics literature. The effect of different police strategies on crime by violent groups has also received only little attention. ${ }^{3}$ We show that while discriminative policing always reduces violence, policing methods that hit members of targeted groups at equal force independently of how violent they are, may, in fact, increase violence.

What characterizes hooligan organizations? It is common that individuals, in addition to the possible preference for violence itself, join supporter clubs to benefit from identity and the social network offered in these clubs (see, e.g., the work by the psychologists Marsh 1978, Marsh and Harré 1978 and sociologists Dunning et al. 2002). Leaders are typically dominant and good at planning and organizing hooligan episodes (Kerr 1994) ${ }^{4}$ and members have to obey the leaders to be included. Dunning et al. (2002, p. 21) writes "In these gangs, ability and willingness to use violence and to fight tend to become criteria for membership of and prestige within the group". Moreover, while the aim is to fight, there are typically norms that restrict the level of violence. ${ }^{5}$

To reflect the empirical evidence of the club structure we set up a model where the leaders may require members to fight in order to stay in the club. Members value identity provided by the supporter club, but they differ in their attitudes towards violence. Members may enjoy fighting until some point, but if leaders require them to fight more, then this reduces their overall utility. However, leaders cannot observe preferences of individual members. Members who like to fight more can, if they are asked to fight more than they want to, always mimic those who prefer less fighting. As a consequence, leaders face a trade-off. They can opt for a small group with a high level of violence per member, or a larger group with less violence per member.

\footnotetext{
${ }^{3}$ Earlier work include Levitt (2004) who argues that the magnitude of policing, rather than the type, affects violence, and Frey (2004) who argues that anti-terrorist deterrence policies may backfire.

${ }^{4}$ Kerr (1994 p. 90) writes "In almost every book or extensive piece that has been written about soccer hooliganism, considerable attention is given to the ringleaders of soccer hooligan violence". Moreover, Kerr (1994, p. 94) quotes the head of the British National Football Intelligence Unit, "I think there is organization and ringleaders. Spontaneous hooliganism occurs a lot less than planned hooliganism".

${ }^{5}$ See e.g. Dal Lago and De Biasi (1994) for Italy and sverigescenen.com for Sweden.
} 
Variable costs of violence reduce in equal proportions the level of violence that leaders can extract from all members. As a result, they increase the price of violence in terms of membership. This relative price effect encourages leaders to reduce the level of violence they require in order to expand membership. Increasing the fixed costs of violence aggravates the mimicking effect, as it reduces relatively more the amount of violence that can be required from the type valuing violence less. Even if the leaders before the change in policy opted for a low level of violence to keep all members in the club, they may now change focus to a high level of violence without the members willing to fight less. Therefore, a harsher governmental policy may finally increase violence.

The previous law and economics literature, like seminal contributions by Becker (1968) and Becker and Landes (1974), concludes that increasing the costs of crime tends to reduce crime. We find that this need not be the case with violent groups. The key explanation for this marked difference is that membership in violent groups is endogenous.

Our findings do not imply that using fixed cost of violence would always be suboptimal. As long as membership does not change, increasing either fixed cost or variable cost both push towards less violence. A utilitarian government may want to use fixed costs as part of the crime-fighting package, for example if these are cheaper to implement. However, our findings suggest a need to study supporter clubs carefully before implementing increases in fixed costs of violence, due to the potential backlash that these may cause.

The paper is related to several strands of the economic literature. Violent supporter clubs remind of criminal gangs in that they are violent, that they serve as a platform for social interaction and because society may aim to abolish them. In contrast to criminal organizations in the economics literature on organized crime (see e.g. Shelling 1984, Konrad and Skaperdas 1997 and Levitt and Venkatesh 2000), we do not focus on illegal economic activity but rather on violence and identity. Akerlof and Kranton (2000) introduce identity to economic modeling and study how it affects economic 
outcomes. We analyze how it affects violence and the society's possibilities to reduce it.

Even though violence associated with supporter clubs has not received any attention in the economics literature, there is a vast literature in other social sciences such as sociology, psychology and ethnography (see e.g. Dunning et al. 1984, Dunning et al. 2002, and Kerr 1994). Interestingly, sociologists and psychologists have for long been arguing also that more policing might lead to more violence in supporter clubs (see e.g. Cohen 1971, Buford 1991 and Kerr 1994). For example, psychologists Adang and Stott, who advised the Dutch police in their preparations for the European Soccer Championship in 2004, state "Indiscriminate, heavy-handed policing can create rather than reduce conflict." According to them, police intervention should be targeted at those fans who are actually misbehaving (Adang and Stott, 2004). While this literature has focused on how police officers stimulate hooligans to fight more, we show in a microfounded model that the reason is due to group dynamics.

The rest of the paper is organized as follows. In Section 2, the basic model is presented and the equilibria derived. Section 3 shows how different types of policing affect violence and section 4 deals with the optimal level of policing. Section 5 concludes.

\section{Supporter Clubs}

\subsection{Game Structure}

A supporter club consists of risk neutral leaders and members. Leaders derive utility from fighting by members and the total number of members. All members derive utility $\alpha$ from belonging to a supporter club, while they differ in their attitudes towards violence. The parameter $\alpha$ captures benefits from a social identity provided by the club or networking possibilities. There are two types of members, differing in their preferred level of fighting. We denote the two types by their ideal points, so that the 
preferred level of fighting by type $i(j)$ is $i(j) .{ }^{6}$ Without loss of generality, $j \geq i \geq 0$. Below this level, additional fighting generates marginal gross benefit equal to unity. However, fighting also generates costs. Violence of amount $v$ generates cost $\lambda v+\gamma$ for those committing it. $\lambda$ is a marginal cost capturing injuries caused by hooligans or the police, being jailed overnight or added into a criminal register, judicial punishment and psychological costs from violence. We assume that $\lambda<1 .^{7} \gamma$ is an additional fixed cost arising from police activity and criminal sanctions for those who belong to supporter clubs and commit violence. It reflects the possibility that any supporter engaging in violence, independently of the level of violence committed, has a probability of incurring the costs mentioned above. For example, using tear gas to disperse a violent crowd hurts those targeted, independently of how much violence they have committed. Formally, cost $\gamma$ is levied on those whose $v>0$. We therefore introduce an indicator variable $D$, so that $D=0$ if $v=0$ and $D=1$ if $v>0 .^{8}$

Even though many hooligans enjoy violence, there are typically norms that restrict it. ${ }^{9}$ A reason for the existence of these norms is presumably that hooligans only enjoy violence up to a certain point. Then, when the threat of severe injuries is too large, they dislike violence. The following utility function we adopt captures these properties.

Total utility for a member of type $k$ who chooses a level of violence $v_{k}$ and is not expelled is

$$
\begin{aligned}
u_{k} & =\alpha, \text { if } v_{k}=0 \\
& =\alpha+(1-\lambda) v_{k}-\gamma, \text { if } 0<v_{k} \leq k \\
& =\alpha+(1-\lambda) k-\lambda\left(v_{k}-k\right)-\gamma, \text { if } v_{k}>k .
\end{aligned}
$$

\footnotetext{
${ }^{6}$ Our results would generalize into more than 2 discrete groups. At the extreme, each potential member could be viewed as a discrete group of size one.

${ }^{7}$ Otherwise, the preferred level of fighting would be zero for all hooligans, which would run against the empirical observation that at least some hooligans actually want to fight.

${ }^{8}$ All our results would remain the same in case $\lambda$ and $\gamma$ would be expected costs from committing violence.

${ }^{9}$ The use of weapons and kicking on people already on the ground are, for example, often considered to be excessive violence (see, e.g., the home page of the violent Swedish hooligan club "Firman Boys", www.sverigescenen.com).
} 
In words, a member receives the utility from networking only if he is not expelled. If he chooses a zero violence, his total utility equals the utility from networking, if not expelled. If he chooses a positive level of violence, he receives a net marginal utility of $1-\lambda$ of violence until his bliss point. After the bliss point, additional violence generates only additional marginal cost $\lambda$. Furthermore, committing violence implies a discrete fixed $\operatorname{cost} \gamma$. The utility of the expelled members is zero.

The number of potential members of type $j$ is $n_{j}$, and the number of members of type $k$ who stay and are not expelled is $m_{k}$, giving as total membership $m=m_{i}+m_{j}$. The number of leaders is normalized to unity. Leaders differ in their valuation of violence.

At the first stage, leaders declare a minimum level of violence $\widehat{v}$ required from members. At the second stage, members decide how much to fight. After observing the level of fighting by individual members, leaders decide whether to keep them or expel them. Leaders cannot distinguish an individual member's private attitude towards violence. This is a reasonable assumption, as members can always lie about their type and state that they like violence less if leaders ask them to fight more than they would like to. Leaders therefore must ask for one level of violence only.

The aggregate level of violence is

$$
V=m_{i} v_{i}+m_{j} v_{j}
$$

Leaders receive utility

$$
u_{l}=\beta m+\theta V
$$

By $\beta>0, \theta>0$, leaders receive a positive utility from the aggregate level of violence by their club members, and from the number of members who stay and give them prestige. One reason why leaders have a reason to care about the number of members, even if members do not, is that leaders are evaluated according to how many followers they have. We call the utility that leaders derive from the number of followers prestige. For the same reason, leaders care also about the aggregate level of violence. 
Leaders may expel those who fight less than they require, in which case the expelled lose identity and receive payoff of zero. ${ }^{10}$ Leaders announce a minimum level of violence required, $\widehat{v}$, and then expel the members who do not fulfill it. Expulsion following defection is necessary to maintain credibility. Violence is supplied and identity is received as a flow. For both types of members, the participation constraint is that the expected utility from membership must be non-negative, implying that requirement

$$
\widehat{v} \leq \frac{\alpha+k-\gamma}{\lambda}
$$

need to be satisfied for type $k$ to stay. We assume for now that $\alpha+i-\gamma>0$, implying that both types of members can be induced to commit at least some violence. The case $\alpha+i-\gamma \leq 0$ is discussed in subsection 3.2.

\section{$2.2 \quad$ Equilibria}

Leaders face two alternative strategies. One is to choose such a level of violence that both types $i$ and $j$ stay, and another to choose such a level that only type $j$ stays. In the first case, leaders choose

$$
\widehat{v}=\frac{\alpha+i-\gamma}{\lambda} \equiv \underline{v}
$$

and in the latter,

$$
\widehat{v}=\frac{\alpha+j-\gamma}{\lambda} \equiv \bar{v}
$$

where $\bar{v}>\underline{v}$. It is never optimal to choose any other level of $\widehat{v}$. To see this, note that if $\widehat{v}<\underline{v}$, or $\underline{v}<\widehat{v}<\bar{v}$, then leaders can increase the required violence without causing members to leave. If $\widehat{v}>\bar{v}$, then all members would leave, resulting in zero utility for leaders. With $\widehat{v}=\underline{v}$, the utility of leaders is

$$
u_{l}=\beta\left(n_{i}+n_{j}\right)+\theta\left[n_{i} \underline{v}+n_{j} \max (\underline{v}, j)\right] .
$$

\footnotetext{
${ }^{10}$ In reality, leaders too sometimes fight. However, adding this assumption would only add notation and not change our results qualitatively.
} 
With $\widehat{v}=\bar{v}$, the utility of leaders is

$$
u_{l}=\beta n_{j}+\theta n_{j} \bar{v}
$$

Lemma 1 below reports that if the number of members with a lower bliss point of violence is sufficiently high, relative to the number of members with a higher bliss point of violence, then choosing $\underline{v}$ is always optimal:

Lemma 1 Choosing $\widehat{v}=\underline{v}$ is optimal for all $\beta \geq 0$ if either $j<\underline{v}$ and

$$
n_{i} \geq \frac{n_{j}(j-i)}{\alpha+i-\gamma}
$$

or if $j \geq \underline{v}$ and

$$
n_{i} \geq \frac{n_{j}(\alpha+j-\gamma-\lambda j)}{\alpha+i-\gamma}
$$

Proof. If $j<\underline{v}$, total level of violence is $\left(n_{i}+n_{j}\right) \underline{v}$ if leaders set $\widehat{v}=\underline{v}$, and $n_{j} \bar{v}$ if leaders set $\widehat{v}=\bar{v}$. Condition (7) follows by inserting the definitions of $\underline{v}$ and $\bar{v}$ into the expression $\left(n_{i}+n_{j}\right) \underline{v} \geq n_{j} \bar{v}$, and rearranging. If $j \geq \underline{v}$, total level of violence is $n_{i} \underline{v}+n_{j} j$ if leaders set $\widehat{v}=\underline{v}$, and $n_{j} \bar{v}$ if leaders set $\widehat{v}=\bar{v}$. Condition (8) follows by inserting the definitions of $\underline{v}$ and $\bar{v}$ into the expression $n_{i} \underline{v}+n_{j} j \geq n_{j} \bar{v}$, and rearranging.

We next analyze those parameter values with which either $\underline{v}$ or $\bar{v}$ might be optimal:

Proposition 1 If $j<\underline{v}$, then it is optimal to choose $\bar{v}$ if and only if

$$
n_{i}<\frac{\theta n_{j}(j-i)}{\beta \lambda+\theta(\alpha+i-\gamma)}
$$

If $j \geq \underline{v}$, then it is optimal to choose $\bar{v}$ if and only if

$$
n_{i}<\frac{\theta n_{j}(\alpha+j-\gamma-\lambda j)}{\beta \lambda+\theta(\alpha+i-\gamma)}
$$

Proof. If $j<\underline{v}$, then total utility of leaders is higher if they set $\widehat{v}=\bar{v}$ if and only if 


$$
n_{i}<\frac{\theta n_{j}(j-i)}{\beta \lambda+\theta(\alpha+i-\gamma)}
$$

If $j \geq \underline{v}$, total utility of leaders is higher if they set $\widehat{v}=\bar{v}$ if and only if

$$
n_{i}<\frac{\theta n_{j}(\alpha+j-\gamma-\lambda j)}{\beta \lambda+\theta(\alpha+i-\gamma)}
$$

According to Proposition 1, leaders choose the level of violence that just keeps members of type 2 and leads to an exit by members of type 1 if this increases aggregate violence, and if the leaders value this increase more than the utility they would derive from type 1 members if they would stay. Note that if $\beta=0,(9)$ becomes (7) and (10) becomes (8). If $\beta>0,(7)$ and (8) are no longer sufficient for (9) and (10) to hold.

Notice that choosing $\widehat{v}=\bar{v}$ would be a dominated strategy if the difference $j-i$ is sufficiently small, or if $n_{j}$ is small. This is intuitive: type $j$ members must be willing to engage in a considerably higher level of violence than type $i$ members for leaders to be willing to forgo prestige and violence they can extract from type $i$ members, in exchange to force type $j$ members to move from $\max (i, \underline{v})$ to $\bar{v}$.

\section{Policing and Violence}

In this section, we analyze the effects of policing on total violence and membership. We analyze first the case in which both types are willing to fight at least to some extent, as in section 2 . We then analyze how the results would change if type $i$ members would rather leave than fight even a little.

\subsection{Both Types Willing to Fight}

Becker (1968) and Becker and Landes (1974) early pointed out that law and order should discourage crime. The higher the cost of committing crime, the less crime is committed. In line with this observation, we find that when the membership in the 
hooligan organizations does not change, violence declines smoothly in both fixed and variable costs of violence.

However, these straightforward comparative statics are only part of the potential effects. A change in policing might encourage leaders to change from one equilibrium membership base to another, as the variable and fixed cost of violence enter the conditions in Proposition 1. When accounting for the endogenous membership, the effects of punishment on the level of violence may become non-monotonic. A marginal increase in the variable cost of violence may lead leaders to shift focus to larger and less violent clubs. On the other hand, a marginal increase in the fixed cost of violence may result in a discrete upward jump in violence because leaders shift focus to a smaller and more brutal organization.

We summarize our findings as three propositions:

Proposition 2 An increase in the variable cost of violence $\lambda$ or in the fixed cost of violence $\gamma$ results in a decrease in the aggregate violence, provided that membership does not change.

Proof. Follows by differentiating (3) and (4) with respect to $\lambda$ and $\gamma$.

Proposition 3 A marginal increase in the variable cost of violence $\lambda$ may result in a downward jump in aggregate violence, associated with an increase in membership.

Proof. Proposition 1 gives us a condition for the leaders to choose a smaller and more violent group. Differentiating the right-hand side of (9) or (10) with respect to $\lambda$, we find that the derivative is negative. Therefore, condition (9) (or (10)) becomes less likely to be fulfilled. This implies that an increase in $\lambda$ causes leaders to switch to larger and less violent groups, for some values of $n_{i}$.

Proposition 4 A marginal increase in the fixed cost of violence $\gamma$ may result in an upward jump in aggregate violence, associated with a decrease in membership, if either $j<\underline{v}$, or $j \geq \underline{v}$ and $\beta \leq \theta\left(\frac{j-i}{\lambda}-j\right)$. If $j \geq \underline{v}$ and $\beta>\theta\left(\frac{j-i}{\lambda}-j\right)$, a marginal increase in the fixed cost of violence $\gamma$ may result in a downward jump in aggregate violence. 
Proof. Proposition 1 gives us a condition for the leaders to choose a smaller and more violent group. Consider first the case $j<\underline{v}$. Differentiating the right-hand side of (9) with respect to $\gamma$, we find that the derivative is positive. Therefore, condition (9) becomes more likely to be fulfilled. This implies that an increase in $\gamma$ causes leaders to switch to smaller and more violent groups, with some values of $n_{i}$. Assume next that $j \geq \underline{v}$. Differentiating the right-hand side of (10) with respect to $\gamma$ gives

$$
\frac{\partial}{\partial \gamma} \frac{\theta n_{j}(\alpha+j-\gamma-\lambda j)}{\beta \lambda+\theta(\alpha+i-\gamma)}=\theta n_{j} \frac{-\beta \lambda+\theta(j-i-\lambda j)}{[\beta \lambda+\theta(\alpha+i-\gamma)]^{2}}
$$

If the nominator is positive (negative), (10) becomes more (less) likely to be fulfilled. This implies that an increase in $\gamma$ causes leaders to switch to smaller and more violent (larger and less violent) groups, for some values of $n_{i}$.

Propositions 2 to 4 have empirically testable implications. Proposition 2 implies that if increased policing is not associated with a change in the size of supporter clubs, then total violence should decrease. Proposition 3 implies that if a small increase in the variable cost of violence, either in the form of policing or tougher sentences, would lead into a large drop in aggregate violence, then this should be accompanied by an increased size of violent supporter clubs.

Proposition 4 implies that if $j<\underline{v}$, then the minimum requirement for fighting binds also for the more violent type. In this case, an increase in the fixed cost of violence may backfire. Proposition 4 then suggests that should a small increase in the fixed cost of violence lead into an increase in aggregate violence, then this should be accompanied by a decreased size of violent supporter clubs. If, on the other hand, $j \geq \underline{v}$, then an increase in the fixed cost of violence may result in either smaller and more violent or larger and less violent groups. The exact conditions for when the jumps in membership occur depend on the relative valuation of violence and prestige. However, the model is general enough to allow for all non-negative values of both valuations. 


\subsection{Only One Type Willing to Fight}

In section 2 and subsection 3.1, we assumed that $\alpha+i-\gamma>0$, implying that both types of members can be induced to commit at least some violence. Assume next that $\alpha+i-\gamma \leq 0$. This implies that the type $i$ members are never willing to fight. If leaders want to keep them, they have to choose $\widehat{v}=0$. In this case, leaders have utility

$$
u_{l}=\beta\left(n_{i}+n_{j}\right)+\theta n_{j} j
$$

If leaders choose $\widehat{v}=\bar{v}$, their utility is

$$
u_{l}=\beta n_{j}+\theta n_{j} \frac{\alpha+j-\gamma}{\lambda}
$$

Choosing the latter is optimal if and only if

$$
\theta n_{j}\left(\frac{\alpha+j-\gamma}{\lambda}-j\right)>\beta n_{i} .
$$

As the left-hand side is decreasing in $\gamma$ and $\lambda$, an increase in either type of policing renders choosing $\widehat{v}=\bar{v}$ less attractive. Thus, there is never backfiring. Therefore, if the costs of violence are sufficiently high, a further increase may suffice to eliminate violence by less violent types altogether. Furthermore, if $\gamma \geq \alpha+j$, a fixed cost of violence is sufficiently high to preclude even violence by more violent types.

\section{Optimal Policing}

Importantly, Propositions 3 and 4 imply that the welfare effects of policing and sentencing can be non-monotonic. To evaluate socially optimal policing, assume that the social welfare function is utilitarian. The hooligans have a social weight $\mu$, such that $\mu \geq 0$. This allows as special cases both a value-neutral utilitarian government who gives the welfare of hooligans an equal weight as to other citizens, as well as a government that does not value the welfare of hooligans at all. Assume that the marginal 
external cost of violence is $\kappa, \kappa>0$, and assume that the cost of implementing the fixed cost $\gamma$ of violence is $C(\gamma)$, so that $C(0)=0$, and $C(\gamma+\delta)>C(\gamma) \forall \gamma \geq 0, \delta>0$. Assume also that the cost of implementing the variable cost $\lambda$ of violence is $D(\lambda)$, so that $D(0)=0$, and $D(\lambda+\delta)>D(\lambda) \forall \lambda \geq 0, \delta>0$. These assumptions imply that the marginal cost of increasing either fixed or variable punishment for violence is strictly positive. The cost functions need not be continuous, allowing some threshold levels, for example it could be that implementing any punishment for violence results already in some fixed implementation cost. The social welfare function can now be written as

$$
S W F=\mu n_{i} u_{i}+\mu n_{j} u_{j}+\mu u_{l}-\kappa V-C(\gamma)-D(\lambda) .
$$

The first term gives the social valuation of the utility of type $i$ potential members. The second term is the social valuation of the utility of type $j$ members, and the third term is the social valuation of the utility of leaders. The fourth term is the external social cost of violence, while the fifth and the sixth terms are the costs of punishing for violence. The socially optimal punishment strategy is such a pair of $\gamma$ and $\lambda$ which maximizes (11). While it is not possible to give explicit solutions for this without specifying functional forms of the costs, our analysis allows identifying a possibility for Pareto improvements, even without establishing any additional assumptions:

Proposition 5 A marginal decrease in the fixed cost of violence results in a Paretoimprovement, provided that it results in larger supporter clubs.

Proof. By Proposition 4, reducing $\gamma$ reduces $V$ if it results in larger supporter clubs. Note that $u_{i}=0$ with both large and small supporter clubs, and thus the utility of type $i$ potential members does not change. With large supporter clubs, $u_{j}>0$ while with small clubs, $u_{j}=0$. Therefore, a marginal decrease in $\gamma$ would improve the welfare of type $j$ members, provided that it results in larger supporter clubs. Also $u_{l}$ is increased, which follows from revealed preferences: After the reduction in the fixed cost of violence, leaders could still have kept the same group size, and increased the required level of violence. If they, instead, preferred to switch to a larger and less 
violent club, then this must have further increased their utility. As $\mu \geq 0$, the social valuation of these gains is non-negative. When aggregate violence is reduced, so are the external costs. Finally, reducing the fixed cost of violence also reduces the cost of law and order to implement it.

An increase in the fixed or variable cost of violence can never generate a Paretoimprovement if $\mu \geq 0$. This is because it unambiguously reduces the utility of leaders. However, punishments for violence can still be justified from utilitarian perspective, provided that the costs of punishment are not prohibitively high, and that the external social cost of violence, measured by $\kappa$, is sufficiently high.

Our welfare results suggest the paramount importance of understanding the group dynamics of violent supporter clubs, before deciding on policy interventions. A wellmeaning intervention may, at worst, be counterproductive.

\section{Conclusion}

In this paper, we introduce a model of hooliganism to study how different sanctions against violence can be expected to affect membership in violent supporter clubs, as well as total violence committed. We compare targeted measures that increase variable costs of violence, and cruder measures which levy a fixed cost on violence, like teargas or punishing any participation in a fight. We analyze the effects of the costs of violence when supporter clubs are highly hierarchical, with leaders deciding how much violence they require from members in order to allow them to stay. We take as our starting point that members receive utility from social identity and differ in their preferences for violence. Leaders obtain prestige by having members and also reap utility when members are violent.

First of all, we find that increasing either fixed or variable cost of violence reduces total violence committed, as long as it does not change total membership in supporter clubs. We find an intriguing asymmetry in how aggregate violence reacts to sanctions when membership changes. A small increase in the variable cost of violence may encourage violent leaders to move away from small and highly violent group to a larger 
and less violent one. Leaders would then reduce the level of violence required sufficiently to attract also those potential members who previously stayed outside due to the high cost of fighting. A small increase in the fixed cost of violence, on the other hand, may trigger a counterproductive response, encouraging leaders to move from a larger and less violent group towards a smaller and more violent one. Then aggregate violence would increase. This result highlights the need to properly study violent supporter groups, or youth gangs for that matter, in order to avoid well-meaning but counterproductive policy responses.

\section{References}

[1] Akerlof, Georg A. and Kranton, Rachel E. (2000), "Economics and Identity", Quarterly Journal of Economics, 115: 715-753.

[2] Adang, Otto and Stott, Clifford (2004), "Psychologists Help Prevent Hooliganism at Euro 2004", The Psychologist, September 1, The Monthly Journal of the British Psychological Society.

[3] Armstrong Gary (1998), Football Hooligans - Knowing the Score (Berg, New York).

[4] BBC, April 5, 2007, "Man Utd condemn police behaviour".

[5] Becker, Gary S. (1968), "Crime and Punishment: An Economic Approach", Journal of Political Economy, 76: 169-217.

[6] Becker, Gary S. and Landes, William M. (1974), Essays in the Economics of Crime and Punishment (Columbia University Press, New York).

[7] Buford, Bill (1991), Among the Thugs (Seker and Warburg, London).

[8] Carnibella, Giovanni, Fox, Anne, Fox, Kate, McCann, Joe, Marsh, James, Mars, Peter (1996), "Football Violence in Europe - A Report to the Amsterdam Group", Mimeo, The Social Issue Research Centre, Oxford. 
[9] Cohen, Stan (1971), Folk Devils and Moral Panics (Paladin, London).

[10] Dal Lago, Alessandro and De Biasi, Rocco (1994), "Italian Football Fans: Culture and Organization", in Football, Violence and Social Identity, Giulianotti, Richard, Bonney, Norman, Hepworth, Mike (eds) (Routledge, London-New York).

[11] Dunning, Eric, Murphy, Patrick and Williams, John (1984), Hooligans Abroad The Behaviour and Control of English Fans in Continental Europe (Routledge and Kean Paul, London).

[12] Dunning, Eric, Murphy, Patrick and Waddington, Ivan (2002), "Towards a Sociological Understanding of Football Hooliganism as a World Phenomenon", in Fighting Fans. Football Hooliganism as a World Problem, Dunning, Murphy, Waddington and Astrinakis (eds.) (University College Dublin Press, Dublin).

[13] Footballnetwork.org, "Preventing Football Hooliganism", accessed May 14, 2007.

[14] Frey, Bruno S. (2004), Dealing with Terrorism - Stick or Carrot? (Edward Elgar Publishing, Inc., MA).

[15] Levitt, Steven D. and Venkatesh, Sudhir (2000), "An Economic Analysis of a Drug-Selling Gang's Finances", Quarterly Journal of Economics, 115: 755-789.

[16] Levitt, Steven D. (2004), "Understanding Why Crime Fell in the 1990s: Four Factors that Explain the Decline and Six that Do Not", Journal of Economic Perspectives, 18: 163-190.

[17] Kerr, John H. (1994), Understanding Soccer Hooliganism, (Open University Press, Bristol, USA).

[18] Konrad, Kai A. and Skaperdas, Stergios, (1997), "Credible Threats in Extortion", Journal of Economic Behavior and Organization, 33: 23-39.

[19] Marsh, Peter (1978), Aggro: The Illusion of Violence, (Dent, London). 
[20] Marsh, Peter and Harré, Rom (1978), "The World of Football Hooliganism", Human Nature, 1: 62-69.

[21] Schelling, Thomas C. (1984), Choice and Consequence: Perspectives of an Errant Economist, (Harvard University Press, Cambridge, MA).

[22] Tacitus (1937) [AD 109], The Annals (translated by John Jackson) (Harvard University Press, Cambridge, Massachusetts).

[23] www.sverigescenen.com, accessed May 14, 2007. 